\title{
REPORT ON THE INAUGURAL MEETING OF THE INTERNATIONAL PHOTOTHERAPY ASSOCIATION (IPTA), JUNE 30TH - JULY 3RD, 2006
}

\author{
Yoshimi Asagai MD \\ Shinano Handicapped Children's Hospital, Suwa City, Nagano, Japan
}

D

ear Colleagues, Dear Friends,

It is with great pleasure and honour that I take up the task of writing this Guest Editorial for Volume 15 Issue 3 of the journal, Laser Therapy. I was delighted to be able to host the inaugural meeting of the International Phototherapy Association (IPTA) in the excellently appointed Rako Hananoi Hotel, Suwa City beside beautiful Lake Suwa, one of the true jewels in the crown of Nagano Prefecture which nestles in the middle of the Japanese Alps. With Suwa City being 750 meters above sea level, the air there has a quality completely different from the major Japanese cities, and the light has a totally different quality which has inspired many artists to come to this region to capture that special light. It was very appropriate then, I thought, for us to hold the first IPTA meeting bathed in this special light, because phototherapy is the central idea of the association, and phototherapy is of course treatment with light', from the two Greek roots which make up the word. This journal is now ratified as the official IPTA journal, and although we have retained the masthead 'Laser Therapy', the contents of the journal are now very firmly centred on all forms of phototherapy and photobiomodulation.

The pure air, wonderful natural hot water resources from the many hot springs and the clear light were among the main reasons why what is now the Shinano Handicapped Children's Hospital was founded in the mountains overlooking Suwa City. As Prof Ohshiro, the Editor-in-Chief of the journal, has often said, 'Light is life: without light there can be no life', and it is up to us, the pioneers of the new frontiers of phototherapy, to make full use of the wonderful clinical phototherapeutic tools which have been discovered, and all those yet remaining to be developed, for the great good of our patients. In this Guest Editorial, I should like to give you a brief report on the IPTA meeting, in the hopes that it will inspire more people to join IPTA, and to come together again in 2008 when the 2nd IPTA meeting will be held in New Zealand under the Presidency of Professor David Baxter, no stranger to Laser Therapy readers.

Twenty symposiasts presented 40 papers over the 2 days of the scientific part of the IPTA meeting, which was held in collaborative cooperation with the 18th annual meeting of the Japan Laser Therapy Association (JaLTA), one of the oldest societies dedicated to laser therapy and photobiomodulation. More than 250 attendees participated in the joint meetings from both Japan and overseas, and enjoyed a very strong scientific programme, tempered with an equally diverse social programme including a full programme for those persons accompanying speakers and meeting attendees.

\section{June 30th}

On the evening of Friday, June 30th, 60 national and international members and their significant others participated in the Welcome Reception in the Restaurant Parie, located on the mountainside over Suwa City and affording wonderful views of Lake Suwa and the surrounding mountains. One of the most well-known pioneers of the laser in surgery and medicine, Professor Isaac Kaplan, together with his wife Masha, was due to attend the meeting as Honorary President of IPTA. Very sadly, due to ill health, Isaac and Masha had to cancel their attendance. However Professor Kaplan sent a message to IPTA members written in the form of an 'Ode to IPTA', which was delivered in fine dramatic style by Professor Narong Nimsakul of Thailand, another well-recognized pioneer in laser surgery and medicine. I was also honored in being able to address the attendees and welcome them to the reception, and Professor Ohshiro also said a few words. To the accompaniment of beautiful vistas over Lake Suwa, very tasty French cuisine and bountiful draughts of excellent wine, we were able to celebrate the formation if the IPTA in grand style. Following the reception, we returned to the hotel where we continued the celebrations vocally in the excellent karaoke bar within the 
Rako Hananoi Hotel. Many participants well-known for their oratorical skills demonstrated equally strong talent in the vocal fields, with an international array of songs from the countries of the overseas guests.

\section{July 1st}

The proverbial worm was certainly not safe from the IPTA early birds, as we gathered at 06:40 in the Bellevue room for the opening remarks of the congress over breakfast, chaired and delivered by myself as the Congress President. This room was aptly named, 'Bellevue' in French being translated into English as 'beautiful view', as this was the only room in the hotel to offer panoramic views over the entire Lake Suwa and its environs.

The meeting then adjourned to the main meeting hall under the co-chair of Professor Leonardo Longo of Italy and Prof Masahito Kawatani of Japan with the first symposium on basic research into pain control. Speakers included Drs Hosokawa, Kataoka, Hanaoka and Kawatani, all from Japan. Symposium 2 was on wound healing, and was moderated by Professor Mary Dyson from the UK, one of the world's internationallyrecognized authorities on wound healing, and Prof Toyoshi Hosokawa from Japan. The speakers comprised an international flavour, with contributions from Prof. Dyson (UK), Prof Mario Trelles (Spain) and Dr Junichiro Kubota (Japan). Due to a previous unbreakable engagement, Dr Trelles was unable to attend and was represented by Dr Glen Calderhead, who has been the international research coordinator at Dr Trelles' Instituto Médico Vilafortuny since 1987.

Symposium 3 continued after the coffee break, on the subject of Pain Control, Chaired by Professor David Baxter of New Zealand who is internationally renowned for his research into physiotherapeutic interventions for pain and injury, and exploration of practical modalities to treat pain. Dr Calderhead for Prof Trelles talked on the use of LLLT and LED phototherapy for postsurgical pain, and Prof Baxter gave a very comprehensive overview on pain control in physiotherapy and sports medicine. Photodynamic therapy (PDT) is an extremely important application under the phototherapy umbrella, and this was the subject of Symposium 4, moderated by Drs Nakamura (Japan) and Shick (Korea) centering on basic research. Five presentations, including international talks from Korea (Jong-Ki Kim and Ahn-Woong Shick) comprised this important section. Symposium 4 presented an international overview of LLLT and phototherapy, looking at the national picture. Countries represented were Italy (Prof Leonardo Longo), Viet Nam (Prof Tran Hau
Khang), Korea (Prof Jin Wang Kim) and Thailand (Prof Narong Nimsakul).

No time during this meeting was wasted, and lunchtime was used for three special lectures on CO2 laser applications, the history of the IPTA and the history of clinical PDT. Symposium 6 continued on maxillofacial applications, chaired by Professor Luciana Lopes from Brazil. Interesting presentations in treatment of tinnitus (Dr Miroslav Prochazka), phototherapy in gingival and periodontal pathologies (Dr Rozana Vieru, Romania) and from Dra Lopes on the evolution of phototherapy in the field of oral medicine gave attendees a great deal of food for thought. The final symposium of the day, No. 7, presented an a-la-carte on circulatory problems, heart disease, bronchial oncology and vitiligo including speakers from India, Russia and Egypt. The Moderator was Prof Krishna Rau from India. That concluded the scientific part of the day's programme.

While the attendees were being scientifically educated, their wives and accompanying persons were having some cultural education during their own programme, which commenced at 10:00 with a tour of places of historical and cultural interest around the area organized by Shimosuwa Tours, including lunch. At 16:00, all attendees and accompanying persons boarded buses for a bus tour around Lake Suwa.

The Grand Hall Paruke in the Hotel Rako Hananoi was the milieu for the Presidential Banquet, to which all attendees were welcomed in grand style by the sounding of the great Alpenorn. A series of welcome remarks were given by dignitaries including $\mathrm{Mr}$. Tanaka, Governor and Head of the Nagano Prefectural Local Government; Mr Aoki, the Mayor of Suwa City; Professor Atsumi, Tokyo, Japan, Honorary IPTA President; and Prof Leonardo Longo, Firenze, Italy, who delivered words of welcome on behalf of Professor Kaplan. We were all treated to a video of the traditional 'Onbashira' festival. This is one of Japan's most unique festivals, held at Suwa Grand Shrine every seven years. Immense logs are cut in the mountains and brought up an extremely steep hill to the shrine where they are erected with sacred white paper attached to the top. This is a test of strength, bravery and endurance and surprised and delighted all international guests, and a not a few of those Japanese attendees who were not Nagano natives.

Having had the intellectual senses fulfilled with this cultural demonstration, our gustatory senses were delighted by an excellent multicourse dinner, featuring many specialities from the area and washed down with Japanese rice wine (sake) from the local breweries. The evening was rounded off with karaoke at which 
international talent was again displayed, in addition to the home-grown Japanese variety, and in traditional form by the forming of a grand circle, and the singing of 'Auld Lang Syne' (translated in Japanese as 'The Light of the Firefly'. Many of us moved to the karaoke bar in the hotel, and continued the festivities until the wee hours.

\section{June 2nd}

Bright and early again, the day's programme started in the same room as the previous day, 'Bellevue', although it might be said that some of the partcipants were not so bright due to their efforts on the previous evening! The first programme consisted of a video of the tour of the grand highlands, Kamikochi, scheduled for that afternoon and which I presented just to whet everyone's appetite. At 07:00 the hands-on workshop was held, run by myself on LLLT in cerebral palsy and Prof Ohshiro on his proximal priority method in LLLT. This was followed by Symposium 8 on sports medicine, chaired by Prof Baxter and Prof Ohshiro. A selection of home-grown and international excellent presentations were given on many aspects of the role of phototherapy in different facets of sports medicine.

After the coffee break, I was honoured to give the Presidential Lecture on 15 years of experience in using LLLT in children with cerebral palsy. Prof Kengo Yamamoto was the moderator. This was followed by Prof Kazuhiko Atsumi who gave the 5th Special Lecture on how biomedical engineering could provide a bridge between modern Western medicine to traditional Chinese medicine, to allow the most fruitful aspects of each to be combined for the good of the patient. Prof Narong Nimsakul moderated. We moved on to Symposium 9, which was on the very important subject of LLLT for infertility, chaired by Dr Shinji Fujii, himself a leading proponent of LLLT for female infertility. The advances made in this field in Japan were well-presented, with a success rate which requires further study and application.

This was followed by the IPTA General Assembly, chaired by Drs Asagai and Ohshiro. The formal foundation of the Association was ratified, as was the official journal, Laser Therapy. After discussion, the 2nd IPTA meeting was agreed to be held in New Zealand in early 2008 with Professor David Baxter confirmed as meeting president and as President-elect of IPTA. Ratification of the IPTA Bylaws, which already existed in draught form, was postponed till a later date under an ad-hoc committee to be formed to deal with them. The post of IPTA Secretary-General was awarded to Prof Leonardo Longo, who accepted the post and promised to give his best efforts to the Association.

The Lunchtime Meeting was another a-la-carte offering, with Penny Smalley and Premysl Fryda as the Moderators, Dr Fryda is the CEO of the European Medical Laser Association, and was extremely interested in strengthening ties between IPTA and EMLA. While Ms Smalley dealt with the regulatory maze from the nursing aspect, Dr Fryda gave an excellent explanation of why ISO certification was a really necessary consideration for all modern laser clinics. To round off the session, Professor K.A. Samoilova presented a condensed version of her vast experience in blood photomodification, backed up by very sound and interesting clinical and basic scientific data.

While we were having our morning meetings and lunch, the ladies were touring the area and visiting more sites of interest (Kirigamine). We all came together at 13:00, when I was very proud and happy to make the closing remarks to what had been a really excellent inaugural IPTA meeting. The final act of the meeting was the obligatory group photograph of the principal attendees and Organizing Committee, refer to Fig 1.

I am the Chairman of the Board of the Shinano Handicapped Children's Hospital, and it was my great pleasure to host all attendees for a tour of the facilities. I am extremely proud of our facilities, and we can offer levels of care for all children, no matter how mildly or how severely they are handicapped: what I consider most important is that we not only look after the children, we also look after their parents, so that we can educate the latter on how best to cooperate with the work we do in the Hospital when they are looking after their children at home. What surprised our visitors most was the unique comprehensive care concept we offer in the hospital, which combines a state with a private component. In line with the World Health Organization's goals, we aim to provide for our patients' total well-being, not only physical and mental, but also spiritual, through including full educational facilities as well as our primary role as a hospital. Many of our patients are profoundly handicapped, and not a few of the visitors were moved to tears by their plight. This was completely counterbalanced by the obvious level of care we offer, and I am extremely proud of our ever-increasing efforts to care for all aspects of the life of the handicapped child, in pleasant, bright and as natural as possible surroundings.

Following the tour, invited guest adjourned to a traditional-style Japanese inn, the Hotel Yakko, where we all donned yukata (a light cotton kimono used for relaxing). The hotel features the outdoor natural hot bath, the rotemburo, and we all participated of this 


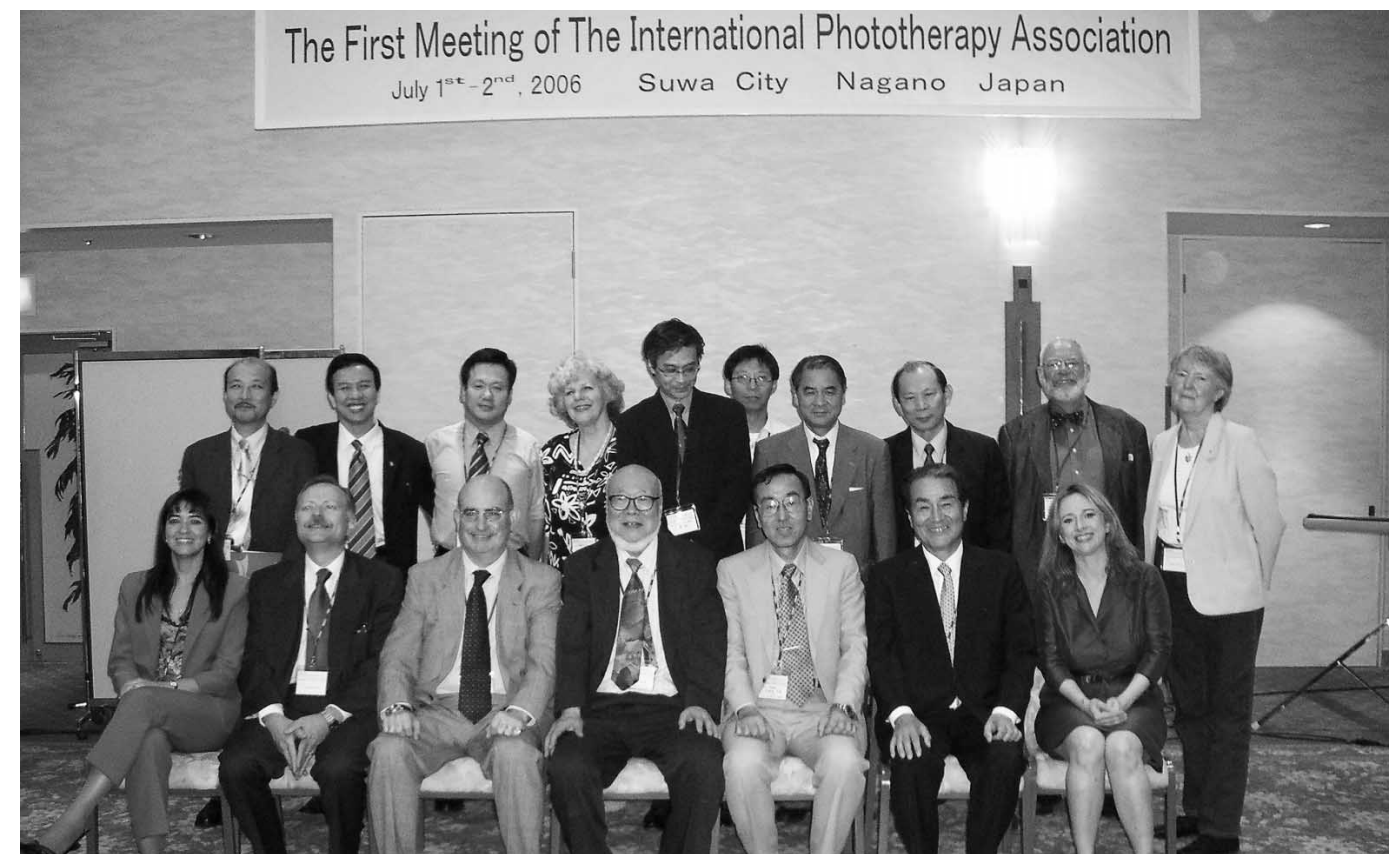

Fig. 1: Photograph of attendees in 1st Meeting of IPTA

warming, relaxing and satisfying ritual. Bathed and suitably relaxed and rosy, 35 of us then attended the farewell party, served on low tables in a traditional Japanese tatami (rush matting) room where we enjoyed a typical Japanese multi-course dinner, served with several examples of the locally-brewed sake, of which we locals are justifiably proud. All international members gave a brief speech, following the toast given by Prof Baxter, and several of the Japanese luminaries were also called on to give a brief speech. The dinner complete, we all adjourned (the more adventurous of us still in kimono) to the 'nijikai', the 'second party place', in the Hotel Sannokaku where we sang karaoke (yet again), danced and made merry. However, it was not too late a night, as we had an early start for the full day tour the following day.

\section{June 3}

Monday, June 3rd, dawned bright and cheerful, a little change from the rather dull and sometimes wet weather of the previous two days, and we were able to set out for our coach trip to Kamikochi, the Great Highlands, one of the most attractive and favorite beauty spots in the Japanese Alps. Once there, we could enjoy refreshing riverside walks in Hodakadake, with the sun filtering through the trees, and with temperatures several degrees below those of Tokyo which is what makes this area so popular for visitors in the summer. A grand lunch was served and enjoyed at the Kamikochi Imperial Hotel, and then we set off for the railway station and our fond farewells. As the coach made its way down through the wonderful scenery, yet more karaoke was enjoyed on board! Bidding each other a fond farewell, we all agreed and promised to meet again in New Zealand for IPTA 2008. It was a great ending to a great meeting.

My own feeling is that this meeting was a hand made' congress, organized completely within and with cooperation between IPTA and JaLTA. A great deal of support was received from the Japan medical Laser Laboratory, through Prof Toshio Ohshiro, and I would like to acknowledge his enormous contribution, and that of his staff, to the successful organization and smooth running of the meeting. I also owe an enormous debt of gratitude to my own staff and colleagues at the Shinano Handicapped Children's Hospital, whose help with the logistics of the meeting was invaluable. At the end of the day, all parties who participated in or who helped with the organizing of the inaugural IPTA meeting were very happy, and that's the way it should be. The most important point for me is that we have strengthened international friendships and relationships, through meeting together to study and discuss light, and that phototherapy certainly has an extremely bright future. In conclusion, may I say how proud I have been to host this IPTA/JaLTA meeting in Suwa City, and I would like to thank most sincerely all those who participated in any way in the meeting's success, not the least my own wife and family! See you all in New Zealand, 2008!!! 